\title{
Bimbingan dan Pelatihan Bahasa Inggris Media Komputer bagi Mahasiswa Santri Masjid Al-Amien
}

\author{
Nur Salam ${ }^{1}$, Abdullah Helmy ${ }^{2}$, Yani Ratnawati ${ }^{3}$, Kun Mustain $^{4}$, Titien Indrianti ${ }^{5}$ \\ ${ }_{1,2,3,4,5}$ Politeknik Negeri Malang \\ e-mail:*1nur.salam@polinema.ac.id, ${ }^{2}$ abdullah.helmy@polinema.ac.id, ${ }^{3}$ yani.ratnawati@polinema.ac.id
}

\begin{abstract}
Abstrak
Di era globalisasi saat ini menuntut mahasiswa yang juga berstatus sebagai santri (mahasiswa-santri) semakin sadar tentang besarnya fungsi dan peran bahasa Inggris dalam rangka meningkatkan kualitas Sumber Daya Manusia (SDM). Sebelum lulus, ketrampilan berbahasa Inggris amatlah penting untuk meningkatkan ketrampilan membaca buku-buku teks berbahasa Inggris dan sekaligus untuk menaikkan prestasi akademiknya. Setelah lulus dari perguruan tinggi nantinya, ketrampilan berbahasa Inggris juga sangat penting dalam mencari pekerjaan. Untuk membantu mahasiswa-santri, maka pelaksana PPM mengadakan pelatihan Bahasa Inggris dengan bantuan media pembelajaran komputer. Hasil yang didapatkan setelah pelaksanaan pelatihan terdapat 80 $\%$ peserta yang telah berhasil meningkatkan ketrampilan berbicara bahasa Inggrisnya tetapi masih ada 20\% yang belum menguasai secara sempurna karena mereka belum mempunyai sarana belajar yang diperlukan untuk belajar dengan menggunakan metode CALL (Computerized Assisted Language Learning). Untuk mengatasi permasalahan tersebut, maka takmir masjid telah melengkapi sarana belajar (wifi) di area masjid.
\end{abstract}

Kata kunci-mahasiswa-santri, pelatihan Bahasa Inggris, media pembelajaran, struktur kalimat

\section{PENDAHULUAN}

Di era globalisasi saat ini, kalangan mahasiswa yang juga berstatus sebagai santri (mahasiswa-santri) semakin sadar tentang besarnya fungsi dan peran Bahasa Inggris baik dalam bentuk ketrampilan bahasa Inggris tulis maupun lisan dalam rangka meningkatkan kualitas Sumber Daya Manusia (SDM). SDM khususnya dari kelompok mahasiswasantri menjadi sangat penting baik sebelum maupun setelah lulus. Sebelum lulus, ketrampilan berbahasa Inggris amatlah penting untuk meningkatkan ketrampilan membaca buku-buku teks berbahasa Inggris dan sekaligus untuk menaikkan prestasi akademiknya [1]. Setelah lulus dari perguruan tinggi nantinya, ketrampilan berbahasa Inggris ini juga penting untuk menghadapi persaingan ASEAN Economic Community (AEC). Bahkan ketrampilan berbahasa Inggris sangat dibutuhkan bagi karyawan perusahaan multinasional [2].

Berdasarkan analisis situasi yang dilakukan oleh pelaksana PPM, para mahasiswa-santri mengaku bahwa metode belajar yang digunakan di kursuskursus bahasa Inggris yang pernah mereka ikuti selalu menggunakan metode yang sama dan waktu yang digunakan tidak fleksibel, dalam artian waktu yang ditetapkan untuk kursus sering bersamaan dengan jadwal belajar mereka di kampus atau kegiatan pengajian di masjid. Untuk mengatasi hal ini kiranya belajar bahasa Inggris dengan bantuan media pembelajaran komputer sangatlah cocok bagi mereka karena pembelajaran seperti ini bisa dilakukan kapan saja sesuai dengan waktu luang mahasiswa-santri [3].

Sebagai konsekuensi logis bagi lembaga keagamaan seperti halnya Masjid Al-Amien Tidar Permai - Karangbesuki - Sukun - Kodya Malang yang juga mendirikan pondok pesantren Masjid AlAmien harus berusaha tidak hanya meningkatkan kualitas ibadah dan pendidikan agama bagi para santrinya tetapi juga kemampuan berbahasa Inggrisnya. Hal ini perlu disadari oleh pengurus masjid karena para mahasiswa-santri nantinya setelah lulus dari perguruan tinggi harus mampu bersaing dalam meniti karir dalam dunia usaha. Salah satu kendala bagi lulusan perguruan tinggi dalam rangka mencari pekerjaan adalah rendahnya keterampilan berbahasa Inggris. Sebagaimana kita ketahui bahwa salah satu persyaratan yang ditetapkan oleh kebanyakan perusahaan dalam merekrut tenaga kerja adalah terampil berbahasa Inggris.

Pada sisi lain, melihat kenyataan bahwa kemampuan berbahasa Inggris sebagai media komunikasi di kalangan mahasiswa masih lemah, para pengajar Bahasa Inggris di Politeknik Negeri 
Malang merasa terpanggil untuk mencari jalan keluar untuk membantu para mahasiswa-santri dalam rangka untuk memenuhi harapan mereka dan membantunya untuk mewujudkan cita-citanya [4]. Berbagai cara telah dilakukan, antara lain:

a) Mengikuti berbagai seminar pengajaran bahasa

b) Mengikuti lokakarya pengajaran ESP (English for Special Purposes)

c) Mengikuti pelatihan-pelatihan pengajaran Bahasa Inggris Teknik

d) Mengundang para pakar pengajaran Bahasa Inggris

e) Mengadakan berbagai diskusi bahasa dan pengajaran bahasa

f) Melakukan penelitian-penelitian pengajaran bahasa

g) Membaca berbagai buku pengajaran bahasa,

h) dll.

Namun, para pengajar Bahasa Inggris di Politeknik Negeri Malang masih belum puas dengan hasil yang dicapai. Akhirnya, sampailah pada suatu usaha untuk memperbaiki sistem pengajaran Bahasa Inggris dengan menggunakan metode Camputer Assisted Language Learning. Mengingat efektifnya pengajaran bahasa Inggris ini, Pelaksana PPM mencoba membantu para mahasiswa- santri di Masjid Al-Amien Tidar Permai - Karangbesuki - Sukun Malang untuk mempersiapkan masa depannya dengan cara meningkatkan ketrampilan berbahasa Inggris.

\section{METODE}

Model pengajaran dengan menggunakan media pembelajaran komputer (computer assisted languange learning / CALL) ini merupakan pengembangan dari model pengajaran sebelumnya. Dengan kata lain pengajaran bahasa dengan "CALL" ini sebenarnya untuk menutupi kekurangan cara belajar bahasa Inggris yang selama ini dilakukan oleh mahasiswa-santri Takmir Masjid Al-Amien Tidar Permai - Karangbesuki - Sukun - Kodya Malang. Kekurangan yang dimaksud di atas adalah metode belajar yang tidak efektif sehingga mahasiswa-santri perlu belajar dengan media pembelajaran komputer yang memungkinkan mereka bisa belajar di mana saja, kapan saja, dan bahkan mereka bisa bertanya kepada orang lain melalui internet.

Dengan menggunakan model pembelajaran Bahasa Inggris sistem CALL ini, mahasiswa-santri bisa:

1. Belajar kapan saja bisa menyesuaikan waktu

2. Belajar materi pelajaran yang mana saja yang menarik perhatian
3. Belajar materi pelajaran yang berbeda sehingga mahasiswa santri bisa belajar berdasarkan kemampuan kebahasaannya

4. Menanyakan hal-hal yang tidak bisa diatasi pada saat belajar di kampusnya

5. Memperbaiki kesalahan-kesalahannya kapan saja walaupun tidak ada bimbingan dosen.

\subsection{Proses Pembelajaran}

Untuk melaksanakan kegiatan ini, pelaksana PPM melakukan 2 (dua) macam proses pembelajaran, yaitu 1) proses pembelajaran di dalam masjid, dan 2) proses pembelajaran di luar masjid.

1) Proses Pembelajaran di dalam Masjid

Proses pembelajaran ini sebenarnya bisa dilaksanakan dimana saja. Tetapi pada kegiatan ini, semua dilaksanakan di masjid untuk memudahkan pelaksanaannya. Kegiatan ini terdiri dari 3 (tiga) bagian, yaitu:

a) Pelaksana PPM memutar CD yang berisi program pembelajaran bahasa Inggris yang ditayangkan di layar. Mahasiswa-santri kemudian mengerjakan sesuai langkah-langkah yang sudah "diatur" dalam program dan menanyakan hal-hal yang mereka belum mengerti,

b) Pelaksana PPM melatih materi "Listening Comprehension" dengan cara menjelaskan materi yang diperlukan dan menjawab pertanyaanpertanyaan yang dilontarkan oleh mahasiswasantri, dan

c) Mahasiswa-santri belajar secara mandiri di laptop yang telah "diisi" dengan program pembelajaran bahasa Inggris dengan CALL. Pelaksana PPM memberikan penjelasan ke masing-masing mahasiswa-santri sesuai dengan kesulitan yang mereka hadapi.

\section{2) Proses Pembelajaran di luar Masjid}

Proses pembelajaran di luar masjid ini merupakan kegiatan belajar mandiri karena memang di luar jam belajar resmi. Mahasiswa-santri bisa belajar kapan saja, di mana saja, dan bagian dari materi mana saja yang mereka minati. Hal ini bisa dilakukan oleh mahasiswa-santri karena mereka diberi CD yang telah berisi program pembelajaran beserta langkah-langkah untuk mengoperasikannya sebagaimana yang telah dijelaskan di atas. Apabila ada mahasiswa-santri yang menemui kesulitan, bisa bertanya kepada mahasiswa-santri yang lainnya atau kepada pelaksana PPM melalui telepon, internet, atau pada saat bertemu di masjid.

Untuk melihat kesiapan mahasiswa-santri dalam melaksanakan program pembelajaran bahasa 
Inggris dengan bantuan komputer ini, terdapat hal-hal yang perlu diperhatikan, antara lain:

- Mahasiswa santri yang tidak memiliki komputer bisa belajar menggunakan komputer milik pelaksana PPM. Oleh karena itu, mahasiswasantri dan pelaksana PPM harus membuat jadwal belajar bahasa Inggris di masjid agar tidak bersamaan dengan kegiatan yang lain yang juga akan menggunakan masjid sebagai tempat pelaksanaan kegiatan. Penjadwalan tersebut harus diperhatikan dengan baik agar program pembelajaran bahasa Inggris dengan bantuan komputer ini tidak hanya berjalan pada awal program tetapi bisa berlangsung sampai akhir program.

- Sehubungan dengan software, pelaksana PPM telah menyiapkan sebagaimana yang telah disampaikan di atas tadi. Namun, pelaksana PPM tetap perlu menyediakan berbagai sumber belajar yang menggunakan bantuan komputer ini agar mahasiswa-santri lebih termotivasi untuk mengisi waktu luangnya untuk belajar bahasa Inggris. Saat pelaksanaan, setiap mahasiswa-santri diberi CD yang telah di-copy-kan program pembelajaran bahasa dengan bantuan komputer.

- Karena belajar dengan model ini mahasiswa-santri perlu menambah jam belajar di luar kampus, pelaksana PPM mendorong mahasiswa-santri untuk mengatur jadwal belajarnya sendiri di luar jadwal resmi dari kampus. Oleh karena itu, sebelum pelatihan perlu diberikan pengertian bahwa pada era global seperti saat ini akan terjadi:

- persaingan yang lebih ketat baik secara kelompok maupun secara individu sehingga kelompok yang memiliki keunggulan kompetitif akan menjadi anggota yang dominan, dan

- hubungan antar kelompok dalam masyarakat global memerlukan bahasa Inggris sebagai alat komunikasi secara luas.

Dari kedua implikasi itu bisa dimengerti bahwa kelompok yang dominan adalah kelompok yang secara kompetitif memang unggul karena ia mempunyai dua ciri pokok, yaitu:

1) profesionalisme yang tinggi baik formal maupun non-formal, dan

2) penguasaan yang baik terhadap bahasa yang terpilih [5].

- Konsekwensi logis dari model pembelajaran yang memerlukan waktu banyak di luar jam belajar di dalam kelas, pelaksana PPM perlu menyediakan waktu luang untuk memberikan pengarahan kepada mahasiswa yang memerlukan bantuan dalam mempelajari materi yang telah dipersiapkan.

- Walaupun mahasiswa bebas belajar bahasa Inggris secara mandiri, pelaksana PPM harus tetap mengikuti "koridor" yang tertera pada CD.

Dari uraiaan di atas bisa disampaikan di sini ringkasan metoda pengembangannya sebagai berikut:

1. Pelaksana PPM mencari dan menemukan kelemahan dari metode pengajaran sebelumnya yang dikenal dengan pembelajaran Bahasa Inggris secara tradisional.

2. Pelaksana PPM mempelajari buku-buku referensi yang membahas tentang belajar bahasa dengan bantuan media pembelajaran komputer (Computer Assisted Language Learning)

3. Pelaksana PPM merancang pengajaran Bahasa Inggris dengan menggunakan bantuan media pembelajaran komputer.

4. Pelaksana PPM mencari materi pengajaran bahasa Inggris di CD yang berisi 5 (lima) bagian, yaitu: 1) Tutorial, 2) Practice, 3) Examination, 4) Review, dan 5) Progression

5. Pelaksana PPM mensosialisasikan dan melatih model pengajaran ini kepada mahasiswa-santri.

6. Pelaksana PPM mempersiapkan media penunjang lainnya agar proses belajar mengajar bisa berjalan dengan baik.

7. Pelaksana PPM memotivasi mahasiswa-santri agar "rela" menggunakan waktu luangnya untuk meningkatkan kemampuan bahasa Inggris dengan bantuan media pembelajaran komputer.

8. Pelaksana PPM mengamati interaksi mahasiswasantri dengan teman-temannya pada saat belajar bahasa Inggris dengan menggunakan bantuan media pembelajaran komputer.

9. Pelaksana PPM merespon pertanyaan dari mahasiswa-santri.

10. Mengevaluasi pelaksanaan model pengajaran ini baik dari interaksi mahasiswa-santri maupun dari hasil latihan mereka.

Selanjutnya untuk menjamin kelangsungan model pengajaran bahasa Inggris dengan bantuan media pengajaran komputer ini, perlu ditanyakan kesiapan mahasiswa-santri dengan mengajukan beberapa pertanyaan, yaitu:

1) Tentang "hardware"

- Apakah semua mahasiswa-santri mempunyai komputer?

- Kalau tidak, apakah kampus menyediakan komputer? 
- Kalau menyediakan, bagaimana mengatur jadwal belajarnya?

- Apakah setiap komputer yang disiapkan kampus sudah dilengkapi dengan "software"?

- Apakah setiap mahasiswa-santri diberi "software"?

2) Tentang "Software"

- Ketrampilan berbahasa apa saja yang akan diajarkan?

- Apakah pelaksana PPM sudah siap dengan "software"nya?

- Bagaimana kualitas "software"nya?

\subsection{Pengacuan Pustaka}

CALL (Computerized Assisted Language

Learning) ini mempunyai 2 (dua) model, yaitu:

a) content-specific dimana pelaksana PPM tidak bisa merubah isi pokok bahasan karena sudah merupakan kaidah kebahasaan yang telah ditentukan, misalnya: ejaan, arti kata, hubungan subyek- predikat, pola kalimat, dll, dan

b) content-free dimana pelaksana PPM bisa menyediakan / menyiapkan pokok bahasan yang ia inginkan sehingga mahasiswa-santri akan mengikuti apa kemauan dari pelaksana PPM.

CALL ini merupakan cara belajar bahasa Inggris yang bisa diterapkan pada ketrampilan menyimak, berbicara, membaca, dan menulis sebagai berikut: "CALL now includes highly interactive and communicative support for listening, speaking, reading and writing, including extensive use of multimedia CD-ROMs and the Internet" [6]. Contoh pengajaran model CALL untuk pengajaran pengucapan (pronunciation) sebagai bagian dari ketrampilan berbicara [7].

CALL dibagi dalam 3 (tiga) fase, yaitu [8]:

1) Behaviouristic: pada fase ini komputer berperan sebagai tutor, artinya komputer akan bertindak sebagai pemberi perintah kepada para mahasiswasantri apa yang harus dipelajari, dikerjakan, dan dilaporkan oleh mahasiswa-santri kepada pelaksana PPM,

2) Communicative: pada fase ini komputer dipakai sebagai alat untuk melatih ketrampilan berbahasa para mahasiswa-santri termasuk di dalamnya adalah:

(i) menggunakan komputer untuk mendorong mahasiswa untuk berdiskusi dalam bahasa Inggris, menulis dalam bahasa Inggris, dan berfikir kritis, dan

(ii) menggunakan komputer sebagai alat untuk mengecek kebenaran penulisan dan benar salahnya kalimat yang telah dibuatnya, dan
3) Integrative: fase ini dianggap sebagai pengenalan pada 2 (dua) inovasi dalam pembelajaran bahasa Inggris yang amat penting, yaitu:

(i) multimedia, dan

(ii) Internet.

Keuntungan utama dari penggunaan multimedia pada pembelajaran bahasa Inggris adalah para mahasiswa-santri akan bisa berlatih empat ketrampilan bahasa, yaitu : reading, writing, speaking dan listening yang terintegrasi dalam satu kegiatan. Sedangkan komputer mempunyai berbagai keuntungan, antara lain: mahasiswa-santri akan bisa berkomunikasi dalam bahasa Inggris dengan sesama mahasiswa-santri atau bahkan dengan pelaksana PPM.

Selain adanya program pelatihan bahasa Inggris sebagaimana tercantum di atas, juga ada permainan kosa kata, "action mazes", petualangan dan simulasi, program penelitian, dan menyusun teks. Di tahun berikutnya bahkan banyak materi pengajaran yang tidak bisa dipresentasikan tanpa adanya bantuan komputer. "Total Cloze" text reconstruction programs such as Storyboard, Fun with Texts, Eclipse, Rhubarb (and many other variants), offering activities that could not be carried out without using a computer [9].

Selain itu CALL juga dibagi menjadi 3 (tiga) kategori, yaitu: 1) Restricted, 2) Open, dan 3) Integrated CALL. The term "Restricted" is more satisfactory since it allows us to refer not only to a supposed underlying theory of learning but also to the actual software and activity types in use at the time, to the teachers' role, to the feedback offered to students and to other dimensions - all were relatively "restricted"..." sedangkan pada kategori "open" adalah umpan balik yang diberikan kepada mahasiswa-santri lebih bersifat terbuka. Selanjutnya pada kategori "integrated" terdapat normalisasi. Artinya bahwa sesuatu yang dulu dianggap merupakan hasil teknologi tinggi tapi saat ini sudah tidak dirasakan lagi bahkan dianggap sesuatu yang biasa [10].

\section{HASIL DAN PEMBAHASAN}

\subsection{Pembahasan}

Pada bagian ini dibahas materi pelatihan yang diuraikan dalam dua kategori, yaitu Listening Comprehension dan English Sentence Structure yang akan meliputi Vocabulary dan English Expressions. Selanjutnya dibahas pula sumber belajar, bahan ajar, kesulitan yang dihadapi oleh peserta pelatihan, dan model tes pada masing-masing kategori. 


\subsubsection{Materi Pelatihan}

Untuk mencapai tujuan pelatihan bahasa Inggris ini perlu adanya materi pelatihan. Materi pelatihan disesuaikan dengan jumlah pertemuan dan tujuan pelatihan, sebagai berikut :

1. Listening Comprehension

a. Sumber Belajar untuk Listening

Comprehension

Beberapa website yang bisa diakses di internet antara lain:

1) http://learnenglishteens.britishcouncil.org/ skills/ Website ini berisi berbagai materi listening yang cukup bervariasi.

2) http://www.elllo.org/00Indexes/TheBigLi st.htm. Website ini berisi slide show, kuis, transcript, serta beberapa audio notes.

3) http://www.eslgold.com/listening.html. Website ini berisi materi untuk belajar Bahasa Inggris.

4) http://learnenglishteens.britishcouncil.org/ freetime/.video-zone. Website ini berisi materi Learn English Teen dari British Council.

5) http://australianetwork.com/englishbites/ rchive 2006.htm. Website ini berisi Learn English with Australia Network.

6) http://www.dailyesl.com/ Website ini berisi Randall 's Cyber ESL.

7) http://www.insideout.net/video/anecdotevideo-player

8) http://learnenglish.britishcouncil.org/en/ Website ini berisi elementary-podcasts.

9) http://www.breakingnewsenglish.com. Website ini berisi materi belajar EFL/ESL.

b. Bahan Ajar untuk Listening Comprehension Bahan ajar untuk pelatihan Bahasa Inggris dalam ketrampilan menyimak ini masih dibatasi pada analisa gambar. Untuk bagian ini, dikenalkan strategi mengerjakan latihanlatihan yang terbagi dalam 4 bagian, yaitu 1) Membuat Asumsi-asumsi,

Mengindentifikasi orang, 3) Mengidentifikasi Benda, dan 4) Mengindentifikasi Kegiatan.

c. Kesulitan Mahasiswa-santri dalam Mempelajari Ketrampilan Menyimak

Berikut beberapa kesulitan yang dihadapi oleh para mahasiswa-santri saat mempelajari bahan untuk ketrampilan menyimak:

1. Tidak dapat memahami pengucapan (pronunciation) kata-kata bahasa Inggris.
2. Tidak dapat mengikuti kecepatan berbicara penutur asli Bahasa Inggris.

3. Tidak memiliki kosa kata yang memadai

4. Tidak memahami struktur kalimat Bahasa Inggris dengan baik

5. Tidak mampu memahami ide pokok percakapan yang diucapkan oleh penutur asli Bahasa Inggris.

d. Model Tes untuk Listening Comprehension

Dalam pelatihan ini, para mahasiswa-santri tidak saja dikenalkan referensi untuk Listening Comprehension yang bisa diakses di internet, materi pelatihan yang bisa dipelajari, dan kesulitan bagi mahasiswasiswa yang mereka hadapi pada saat belajar Listening Comprehension, serta model tesnya. Berikut model untuk pelatihan Listening Comprehension :

1) Sound Discrimination Tess

Tes ini sangat cocok untuk para mahasiswa-santri yang tingkat pemahaman Bahasa Inggrisnya rendah. Tes ini berfokus untuk perbedaan fonem. Pada bagian ini ada dua macam, yaitu:

a. Word Sets in Isolation

b. Words in Context

2) Auditory Comprehension Tess

Tes ini sangat cocok untuk para mahasiswa-santri yang tingkat pemahaman Bahasa Inggrisnya menengah sampai mahir. Tes ini berfokus untuk pemahaman suatu berita atau percakapan. Pada bagian ini ada empat macam, yaitu:

a. Directions Requiring Action Responses

b. Questions and Statements (Multiplechoice)

c. Dialogues (Multiple-choice)

d. Lectures (Multiple choice)

2. English Sentence Structure

a. Sumber Belajar untuk English Sentence Structure

Beberapa website yang bisa diakses di internet antara lain:

1) Sentence Structure and Types of Sentences -

Grammar-Academic

https://academicguides.waldenu.edu/writingc

enter/grammar/sentencestructure

2) Sentence Patterns - The Writing Center https://writingcenter.unc.edu/tips-andtools/sentence-patterns/ 
3) Sentences: Sentence Structure: The Fab Four - Infoplease

https://www.infoplease.com/languagearts/grammar-and-spelling/sentencessentence-structure-fab-four

4) Basic English sentence structure|Wordy https://www.wordy.com/writersworkshop/basic-english-sentence-structure/

5) Sentence Structure: How to Build Sentences and Use the Correct ... https://www.fluentin3months.com/sentencestructurel

b. Bahan Ajar untuk English Sentence Structure Bahan yang diberikan dalam pelatihan ini dibatasi hanya Struktur Kalimat Bahasa Inggris.

1) Simple Present Tense

2) Present Continuous Tense

3) Simple Past Tense

4) Present Perfect Tense

5) Present Prefect Continuous Tense

6) Past Continuous Tense

7) Past Perfect Tense

8) Past Perfect Continuous Tense

9) Present Future Tense

10) Future Continuous Tense

11) Future Perfect Tense

12) Future Perfect Continuous Tense

13) Past Future Tense

14) Past Future Continuous Tense

15) Past Future Perfect Tense

16) Past Future Perfect Continuous Tense

c. Penyebab Kegagalan Mahasiswa-santri dalam Mempelajari English Sentence Structure

Berdasarkan pengamatan pelaksana PPM dan pengakuan mahasiswa-santri yang mengikuti pelatihan Bahasa Inggris ini, ditemukan beberapa penyebab kegagalan mahasiswa-santri dalam mempelajari English Sentence Structure sebagaimana yang terurai di bawah ini:

1. Mahasiswa-santri belum mempunyai pengetahuan yang cukup tentang English Sentence Structures sebelum mengikuti pelatihan Bahasa Inggris ini.

2. Mahasiswa-santri sebelumnya kurang berminat untuk belajar English Sentence Structures.

3. Mahasiswa-santri mengaku kurang waktu dalam mempelajari English Sentence Structures.

4. Mahasiswa-santri mempunyai pemahaman yang keliru tentang manfaat dalam mempelajari English Sentence Structures.

5. Mahasiswa-santri mengaku tidak mempunyai sarana belajar yang cukup.

6. Mahasiswa-santri lemah dalam kedisiplinan belajar Bahasa Inggris.

d. Model Tes untuk English Sentence Structures. Setelah mengikuti pelatihan Bahasa Inggris ini, para mahasiswa-santri perlu dikenalkan pada tipe atau model tes English sentence structures untuk membantu mereka mengembangkan pengetahuannya. Adapun model tes yang biasa ditemui adalah: 1) Multiple choice, 2) Transformation, 3) Gapfilling, 4) Cloze, dan 5) Error correction

\subsection{Luaran yang Dicapai}

Setelah dilakukan pelaksanaan Pelatihan Bahasa Inggris bagi mahasiswa-santri Masjid AlAmien Tidar Permai - Sukun - Karangbesuki - Kota Madya Malang dengan sistem CALL (Computerized Assisted Language Learning) diperoleh hasil yang maksimal.

\subsubsection{Hasil yang Dicapai}

Pelatihan Bahasa Inggris ini telah dilaksanakan dengan sebaik-baiknya dengan rincian sebagai berikut:

1. Ada delapan dari sepuluh peserta pelatihan $(80$ $\%$ telah berhasil mempelajari pengembangan Ketrampilan berbahasa Inggris dengan bantuan komputer yang ditunjukkan dengan kemampuan dalam menyampaikan idenya dalam Bahasa Inggris.

2. Walaupun telah dinyatakan berhasil bukan berarti mereka tidak mempunyai kendala dalam mengembangkan ketrampilan berbahasa Inggris mereka setelah selesainya pelatihan ini. Beberapa hal berikut ini yang menjadi kendala:

a. Dua dari sepeluh peserta $(20 \%)$ tidak mempunyai laptop untuk mempraktekkan cara belajar Bahasa Inggris dengan sistem CALL.

b. Semua peserta $(100 \%)$ belum mempunyai tempat yang layak untuk belajar Bahasa Inggris dengan menggunakan sistem CALL ini karena mereka tinggal di area masjid. Namun, takmir akan menyediakan wifi di area masjid agar para mahasiswa-santri bisa memanfaatkannya.

c. Dua dari sepuluh peserta $(20 \%)$ masih terbiasa belajar dengan sistem tradisional 
sehingga masih kesulitan menggunakan sistem CALL.

d. Peserta belum mempunyai tutor yang berkualitas untuk mengembangkan ketrampilan berbahasa Inggris mereka.

\section{KESIMPULAN}

Dari uraian di atas, mulai dari analisis situasi, permasalahan yang dihadapi oleh mitra PPM ini, proses pelatihan, metode pelaksanaan, materi pelatihan sampai testimoni para peserta bisa disampaikan kesimpulan sebagai berikut:

1. Pelatihan Bahasa Inggris bagi mahasiswa-santri seperti ini sangat bermanfaat bagi peserta karena mereka telah mengetahui cara belajar Bahasa Inggris dengan lebih efektif dan efisien. Hal ini bisa dilihat dengan adanya $80 \%$ dari peserta yang telah mampu menggunakan bahasa dengan baik. Dan, terpenuhinya prasana pembelajaran bahasa Inggris dengan menggunakan media pembelajaran komputer yang disediakan oleh takmir

2. Kendala dalam pelaksanaan pelatihan ini bisa dikatakan tidak terlalu berat karena pada awalnya hanya ada $20 \%$ dari peserta yang belum mempunyai sara belajar yang memadai. Namun hasil dari pelatihan ini cukup membanggakan karena mereka sudah bisa belajar dengan baik karena telah terpenuhinya sarana belajar dan telah dikuasainya cara belajar dengan menggunakan sistem CALL ini.

\section{SARAN}

Untuk kesempurnaan hasil belajar bahasa Inggris dengan sistem CALL ini, perlu disarankan sebagai berikut:

1. Peserta telah memiliki perangkat yang dibutuhkan dalam pelatihan Bahasa Inggris.

2. Peserta mempunyai kemauan untuk merubah cara belajar Bahasa Inggris yang tradisional.

3. Waktu pelaksanaan harus lebih panjang dan terpolakan.

4. Peserta harus mau menyediakan waktu luang untuk belajar Bahasa Inggris.

5. Peserta dan pelaksana PPM lebih disiplin.

6. Pelaksana dan peserta harus memiliki komitmen yang sama untuk pelaksanaan pelatihan Bahasa Inggris.

\section{UCAPAN TERIMA KASIH}

Kami mengucapkan terima kasih kepada Direktur Politeknik Negeri Malang dan kepala P2M Polinema yang telah memberi kepercayaan dan dukungan dana kepada kami untuk melaksanakan kegiatan Pengabdian Pada Masyarakat ini, juga kepada Ketua Takmir Masjis Al-Amien yang telah bersedia sebagai mitra kerja kami.

\section{DAFTAR PUSTAKA}

[1] Salam, N., dkk., 2009, Faktor-Faktor Yang Mempengaruhi Keberanian Mahasiswa Teknik Sipil- Politeknik Negeri Malang untuk Berkomunikasi dalam Bahasa Inggris, Politeknik Negeri Malang.

[2] Kaur, S., Marie, C., 2009, Analysing The English Language Needs Of Human Resource Staff In Multinational Companies. English for Specific Purpose, Academia.edu.

[3] Salam, N., dkk., 2008, Model Pengajaran Bahasa Inggris dengan Menggunakan Media Pembelajaran Komputer, Politeknik Negeri Malang.

[4] Imron, A., 1997, Penerapan Metode Aktif Sebagai Salah Satu Alternatif untuk Meningkatkan Kemampuan Berbahasa Inggris Mahasiswa Jurusan Teknik Listrik Politeknik Universitas Brawijaya Malang, Politeknik Universitas Brawijaya, Malang.

[5] Huda, N., 1999, Peningkatan Penguasaan Bahasa lnggris untuk Menghadapi Globalisasi, Bahasa dan Seni, 27, 1, Februari, 1 -17.

[6] Davies, G. \& Bruzzone, M., 2004, Fun with Texts Version 4.0 (new multimedia version), Maiden head, Camsoft.

[7] Davies, G., 1992, Computer Assisted Language Learning, In Embleton, D. \& Hagen, S., (eds.) Languages In International Business: A Practical Guide, Hodder and Stoughton, London.

[8] Warschauer, M., 1996, Computer-Assisted Language Learning: An Introduction, In Fotos, S., (ed.) Multimedia language teaching, Logos, Tokyo.

[9] Levy, M., 1997, CALL: context and conceptualization, Oxford University Press, Oxford. 
[10] Bax, S., 2003, CALL--Past, Present, and Future. System: An International Journal of Educational Technology and Applied Linguistics, $\quad 31(1), \quad$ 13-28. , from https://www.learntechlib.org/p/96413/. 